\title{
Urinary Retinol Binding Protein (RBP) Level as an early Biomarker of Diabetic Nephropathy in type 2 Diabetic Patients
}

\author{
Nilly Helmy Abdallah ${ }^{a}$ Mahmoud Farid Kamel ${ }^{a}$, Abdelrahman Gamal Abdelaziz $^{a}$, Rehab Muham- \\ mad Abd Elkareem ${ }^{b}$ \\ ${ }^{a}$ Internal Medicine department, Faculty of Medicine, Beni-Suef University, Egypt \\ ${ }^{\mathrm{b}}$ Clinical Pathology department, Faculty of Medicine, Beni-Suef University, Egypt
}

\begin{abstract}
:
Background: Diabetes mellitus continues to be an important clinical problem throughout the world In $2014,8.5 \%$ of adults aged 18 years and older had diabetes. In 2015, diabetes was the direct cause of 1.6 million deaths. Objectives: To investigate the role of retinol binding protein (RBP) in the early stage of diabetic nephropathy, in patients with type 2 diabetes mellitus (T2DM). Methods: This cross-sectional observational study recruited patients with longstanding T2DM and healthy control subjects. Patients with T2DM were further stratified based on their urine albumin-creatinine ratio (UACR). Urinary concentrations of RBP were determined using an enzyme-linked immunosorbent assay.
\end{abstract}

Key words: Retinol, Diabetic Nephropathy, Albuminuria biomarker, RBP.

\section{Introduction}

Diabetes mellitus continues to be an important clinical problem throughout the world [1]. As type two diabetes mellitus (T2DM) progresses, various complications will emerge in patients with this disease, including nephropathy [2]. Diabetic nephropathy (DN) occurs in 20\%$40 \%$ of all patients with diabetes mellitus, affecting the morbidity and mortality of diabetic patients [3]. Interestingly, in chronic cases of diabetic nephropathy, renal function correlates better with the degree of tubule-interstitial injury rather than with glomerular lesions, suggesting that researchers should look for tubular biomarkers in order to identify patients with diabetic nephropathy [4]. There has been a growing interest in identifying alternative biomarkers that might provide a sensitive and rapid means of detecting the progression of diabetic nephropathy. In this regard, various investigators have proposed biomarkers that reflect tubular damage [5]. Urinary RBP has been identified 
as a biomarker of proximal tubular dysfunction. Previous studies have shown that the levels of both serum and urine RBP were increased in patients with diabetes [6].

\section{Patients and methods:}

Patient group: 100 participant (45 male and 55 female) 60 patients (28 males and 32 female) selected from Internal Medicine Department in BeniSuef University Hospital in the period from July 2018 to December 2018. They were divided into the following groups: Group I; 20 Type 2 Diabetic patients with no albuminuria, Group II; 20 Type 2 Diabetic patients with micro-albuminuria, Group III; 20 Type 2 Diabetic patients with macroalbuminuria.

Inclusion criteria: This cross-sectional observational study recruited patients with longstanding T2DM and healthy control subjects. Patients with T2DM were further stratified based on urine albumin-creatinine ratio (UACR) and estimated glomerular filtration rate (eGFR). Serum concentrations of Adipokine zink alpha-2glycoprotein (RBP) were determined using an enzyme-linked immunosorbent assay.

Exclusion criteria: Patients with T2DM were excluded when renal diseases attributable to other causes were suspected. Therefore, exclusion criteria included the presence of:

- Haematuria.

- Renal insufficiency of unexplained origin.

- Urinary tract infection.

- History of rapidly progressive renal failure.

- Glomerulonephritis.

- Polycystic kidney disease.
Ethics: The study was performed after approval of local ethical committee of Beni-Suef university hospital. Written informed consent was taken from every patient before being included in the study.

Statistical analysis: Data will be statistically described in terms of mean standard deviation (SD), or frequencies (number of cases) and percentages when appropriate. P values less than 0.05 will be considered statistically significant. All statistical calculations will be done using computer program SPSS (Statistical Package for the Social Science; SPSS Inc., Chicago, IL, USA) release 15 for Microsoft Windows (2007).

Control group: In addition, 40 healthy volunteer persons (14 males and 26 female) chosen as control group. They were age and sex matched. Age ranges from twenty to eighty years old.

\section{All participants were subjected to:}

1- Careful history taking with special stress on diabetic manifestations, complications and treatment and family history.

2- Clinical examination.

3- Routine laboratory investigations including : Serum samples were analyzed for total cholesterol, high-density lipoprotein cholesterol (HDL-C), low-density lipoprotein cholesterol (LDL-C), triglycerides, glucose, C-reactive protein (CRP), creatinine and blood urea nitrogen $(\mathrm{BUN})$, using an automated biochemical analyzer.

4- Special investigations: Serum concentrations of RBP were determined using an enzymelinked immunosorbent assay (ELISA). 


\section{3- Aim of study:}

To study that retinol binding protein (RBP) might be a potentially useful biomarker for early diagnosis of diabetic nephropathy in patients with type 2 Diabetes mellitus.

\section{Methods:}

This cross-sectional observational study recruited patients with longstanding T2DM and healthy control subjects. Patients with T2DM were further stratified based on their urine albumin-creatinine ratio (UACR). Serum concentrations of RBP were determined using an enzyme-linked immunosorbent assay.

Specimen requirements: Urine-collect sue a sterile container, centrifuge at the speed of 2000-3000 rpm for 20-min. Remove supernatant, if precipitation appeared, Centrifuge again. The Operation of Hydrothorax and cerebrospinal fluid reference to it. Assay immediately or aliquot and store samples at $-20^{\circ} \mathrm{C}$ or $-80^{\circ} \mathrm{C}$.

\section{Statistical analysis of the data collected}

All statistical analyses were performed using the SPSS ${ }^{\circledR}$ statistical package, version 17.0 (SPSS
Inc., Chicago, IL, USA) for Windows ${ }^{\circledR}$. All data were presented as mean \pm SD. Spearman's rank correlation coefficient analysis was used to establish the association between urinary RBP concentrations and the other parameters. The comparison of urinary RBP concentrations among the different groups was performed by either Student's $t$-test or one-way analysis of variance. A $P$-value $<0.05$ was considered to be statistically significant.

\section{Results}

Table (1) demonstrates the demographic characteristics of patients with type 2 diabetes mellitus $(n=60)$ and healthy control subjects $(n=20)$ who participated in a study. Patients and healthy subjects were matched in age and sex distribution without a statistically significant difference. Healthy control subjects distributed as 7 males and 13 females with an average age of 50.15 \pm 9.3 (SD) years; and patients with type II DM distributed as 28 males and 32 females with an average age of $50.98 \pm 8.9$ (SD) years.

\begin{tabular}{|c|c|c|c|c|}
\hline & $\begin{array}{c}\text { Healthy Control } \\
n=40\end{array}$ & $\begin{array}{l}\text { Patients with Type } 2 \text { DM } \\
n=60\end{array}$ & TOTAL & $p$-value* \\
\hline \multicolumn{5}{|l|}{ Age (years); } \\
\hline Mean \pm SD & $50.15 \pm 9.3$ & $51.27 \pm 8.8$ & $50.98 \pm 8.9$ & \multirow[t]{3}{*}{$0.631^{\mathrm{a}}$} \\
\hline Minimum & 35 & 35 & 35 & \\
\hline Maximum & 72 & 72 & 72 & \\
\hline \multicolumn{5}{|l|}{ Sex; N (\%) } \\
\hline Male & $7(35 \%)$ & $28(46.7 \%)$ & $35(43.8 \%)$ & \multirow[t]{2}{*}{$0.440^{\mathrm{b}}$} \\
\hline Female & $13(65 \%)$ & $32(53.3 \%)$ & $45(56.3 \%)$ & \\
\hline
\end{tabular}

Table (1) ${ }^{*} p$-value $\leq 0.05$ is considered significant.

${ }^{a}$ analyzed by Independent Sample t-test, ${ }^{b}$ analyzed by Chi-Square $\left(\chi^{2}\right)$ test. 
Table (2): Clinical Examination of the Studied Population; ( $=100)$ :

It illustrates clinical examination data for the studied population. BMI, SBP and DBP all were significantly higher among patients with type II DM.

\begin{tabular}{|c|c|c|c|c|}
\hline & $\begin{array}{l}\text { Healthy Control } \\
\quad n=40\end{array}$ & $\begin{array}{l}\text { Patients with Type } 2 \text { DM } \\
n=60\end{array}$ & TOTAL & p-value* \\
\hline \multicolumn{5}{|c|}{ BMI; $\left(\mathrm{kg} / \mathrm{m}^{2}\right)$} \\
\hline Mean \pm SD & $26.68 \pm 3.3$ & $31.11 \pm 4.1$ & $30.00 \pm 4.3$ & \multirow[t]{3}{*}{ 0.001* } \\
\hline Minimum & 22 & 23 & 22 & \\
\hline Maximum & 24 & 43 & 43 & \\
\hline \multicolumn{5}{|l|}{ SBP; (mmHg) } \\
\hline Mean \pm SD & $113.00 \pm 16.9$ & $128.98 \pm 14.8$ & $124.98 \pm 16.7$ & \multirow[t]{3}{*}{ 0.001* } \\
\hline Minimum & 90 & 100 & 90 & \\
\hline Maximum & 150 & 159 & 159 & \\
\hline \multicolumn{5}{|c|}{ DBP; (mmHg) } \\
\hline Mean \pm SD & $75.50 \pm 6.9$ & $83.00 \pm 10.6$ & $81.13 \pm 10.3$ & \multirow[t]{3}{*}{ 0.004* } \\
\hline Minimum & 70 & 60 & 60 & \\
\hline Maximum & 90 & 100 & 100 & \\
\hline
\end{tabular}

Table (2) $B M I=$ Body Mass Index, $S B P=$ Systolic Blood Pressure, DBP=Diastolic Blood Pressure ${ }^{*} p$-value $\leq 0.05$ is considered significant by Independent Sample t-test

Table (3): Laboratory Assessment of Blood Glucose Level in the Studied Population; (N=100):

It illustrates laboratory assessment data of blood glucose level for the studied population. FBS, 2h PP and HbA1C. All were significantly higher among patients with type II DM.

\begin{tabular}{|c|c|c|c|c|}
\hline & $\begin{array}{c}\text { Healthy Control } \\
n=40\end{array}$ & $\begin{array}{l}\text { Patients with Type } 2 \text { DM } \\
n=60\end{array}$ & TOTAL & p-value* \\
\hline \multicolumn{5}{|c|}{ FBS; (mmol/L) } \\
\hline Mean \pm SD & $96.95 \pm 7.8$ & $235.23 \pm 91.5$ & $200.66 \pm 99$ & \multirow[t]{3}{*}{ 0.001* } \\
\hline Minimum & 87 & 120 & 87 & \\
\hline Maximum & 110 & 480 & 480 & \\
\hline \multicolumn{5}{|c|}{ 2h PP; (mmol/L) } \\
\hline Mean \pm SD & $128.90 \pm 9.3$ & $313.43 \pm 107.7$ & $267.30 \pm 123$ & \multirow{3}{*}{ 0.001* } \\
\hline Minimum & 111 & 163 & 111 & \\
\hline Maximum & 140 & 578 & 578 & \\
\hline \multicolumn{5}{|l|}{ HbA1C; (\%) } \\
\hline Mean \pm SD & $5.04 \pm 0.6$ & $8.6 \pm 1.4$ & $7.7 \pm 2$ & \multirow[t]{3}{*}{ 0.001* } \\
\hline Minimum & 4 & 6.30 & 4 & \\
\hline Maximum & 6 & 13 & 13 & \\
\hline
\end{tabular}

Table (3) $F B S=$ Fasting Blood Sugar, 2 h PP= 2 Hours Post Prandial, HbAlC= Glycated hemoglobin. ${ }^{*} p$-value $\leq 0.05$ is considered significant by Independent Sample t-test. 
Table (4): Serum Electrolytes and Kidney Function Tests in the Studied Population; (N= 100):

Table (4) illustrates the Serum Electrolytes and Kidney Function Tests in the Studied Population; no statistically significant differences were detected between healthy control subjects and type II DM patients regarding serum $\mathrm{N}$ (sodium) and serum $\mathrm{k}$ (potassium) levels. Blood urea nitrogen (BUN) was significantly higher among patients with type II DM. Estimated glomerular filtration rate (eGFR) was significantly higher among healthy control subjects. Creatinine and Albumin to Creatinine Ratio (ACR) were significantly higher among patients with type II DM.

\begin{tabular}{|c|c|c|c|c|}
\hline & $\begin{array}{l}\text { Healthy Control } \\
\quad n=40\end{array}$ & $\begin{array}{l}\text { Patients with Type } 2 \text { DM } \\
n=60\end{array}$ & TOTAL & p-value* \\
\hline \multicolumn{5}{|l|}{$\mathrm{Na}:(\mathrm{mEq} / \mathrm{L})$} \\
\hline Mean \pm SD & $138.85 \pm 3$ & $139.73 \pm 3.1$ & $139.51 \pm 3.1$ & \multirow[t]{3}{*}{0.273} \\
\hline Minimum & 134 & 134 & 134 & \\
\hline Maximum & 144 & 146 & 146 & \\
\hline \multicolumn{5}{|l|}{$\mathrm{K} ;(\mathrm{mmol} / \mathrm{L})$} \\
\hline Mean \pm SD & $4.01 \pm 0.4$ & $5.03 \pm 6.1$ & $4.77 \pm 5.3$ & \multirow[t]{3}{*}{0.458} \\
\hline Minimum & 3.50 & 3.50 & 3.50 & \\
\hline Maximum & 4.90 & 39 & 39.0 & \\
\hline \multicolumn{5}{|l|}{ BUN; (mg/dl) } \\
\hline Mean \pm SD & $13.50 \pm 3.2$ & $17.11 \pm 7.9$ & $16.21 \pm 7.2$ & \multirow[t]{3}{*}{0.050} \\
\hline Minimum & 7 & 10 & 7 & \\
\hline Maximum & 22 & 69 & 69 & \\
\hline \multicolumn{5}{|c|}{ e-GFR; $\left(\mathrm{ml} / \mathrm{min}\right.$ per $\left.1.73 \mathrm{~m}^{2}\right)$} \\
\hline Mean \pm SD & $79.66 \pm 18.5$ & $65.61 \pm 18.5$ & $69.13 \pm 19.3$ & \multirow[t]{3}{*}{0.006} \\
\hline Minimum & 52.90 & 31.30 & 31.30 & \\
\hline Maximum & 132.80 & 127.90 & 132.80 & \\
\hline \multicolumn{5}{|c|}{ Creatinine; (mg/dl) } \\
\hline Mean \pm SD & $0.96 \pm 0.1$ & $1.14 \pm 0.2$ & $1.09 \pm 0.2$ & \multirow[t]{3}{*}{0.001} \\
\hline Minimum & 0.15 & 0.70 & 0.70 & \\
\hline Maximum & 0.70 & 1.80 & 1.80 & \\
\hline \multicolumn{5}{|l|}{ ACR } \\
\hline Mean \pm SD & $14.86 \pm 9.6$ & $258.33 \pm 286.45$ & $196.4 \pm 269.4$ & \multirow[t]{3}{*}{0.001} \\
\hline Minimum & 4.80 & 3.40 & 3.40 & \\
\hline Maximum & 33 & 997 & 997 & \\
\hline
\end{tabular}

Table (4) $N a=$ Sodium, $K=$ Potassium, $B U N=$ Blood urea nitrogen, $e-G F R=$ estimated glomerular filtration rate, $A C R=$ Albumin to Creatinine Ratio.

${ }^{*}$-value $\leq 0.05$ is considered significant by Independent Sample t-test.

Table (5): urinary Concentration of Retinol Binding Protein (RBP) in the Studied Population; (N= 100): Table (5) demonstrates that mean urinary Concentration of Retinol Binding Protein (RBP) was higher in patients with type II DM as compared with healthy control subjects (6.91 \pm 0.4 vs. 6.35 $\pm 0.5)$ in patients and controls respectively; but with no statistically significant differences ( $\mathrm{P}>0$ $.05)$. 


\begin{tabular}{|c|c|c|c|c|}
\hline & $\begin{array}{c}\text { Healthy Control } \\
\mathbf{n = 4 0}\end{array}$ & $\begin{array}{c}\text { Patients with Type 2 DM } \\
\mathbf{n = 6 0}\end{array}$ & TOTAL & \multirow{2}{*}{$\boldsymbol{p}_{\text {-value }}$ * } \\
\cline { 1 - 4 } RBP; & $6.35 \pm 0.5$ & $6.91 \pm 0.4$ & $6.77 \pm 2.7$ & \multirow{2}{*}{0.395} \\
\cline { 1 - 3 } Mean \pm SD & 1.40 & 1.20 & 1.20 & \\
\hline Minimum & 8.60 & 11.50 & 11.50 & \\
\hline Maximum &
\end{tabular}

Table (5) *p-value $\leq 0.05$ is considered significant by Independent Sample t-test

Table (6): urinary Concentration of Retinol Binding Protein (RBP) among Three Subgroups of Type II DM Patients; $(\mathbf{N}=\mathbf{6 0})$ : According to the UACR, patients with type II DM were stratified into three subcategories; a normal albuminuria group, micro-albuminuria group and macroalbuminuria group. There was a statistically significant difference in mean \pm SD urinary Concentration of Retinol Binding Protein (RBP) between the three subgroups (Overall p-value $=0.001)$. Macro albuminuria subgroup had the highest serum level of RBP followed by Micro albuminuria subgroup. By applying post-hoc (LSD) analysis to identify which pairs of means were statistically different; urinary Concentration of Retinol Binding Protein (RBP) was significantly higher among Macro albuminuria subgroup vs. Norm albuminuria $(\mathrm{p}$-value $=\mathbf{0 . 0 0 1})$ and also was significantly higher among Macro albuminuria subgroup vs. Micro albuminuria ( $\mathrm{p}$-value $=\mathbf{0 . 0 2 0})$. Urinary Concentration of Retinol Binding Protein (RBP) was significantly higher among Micro albuminuria subgroup vs. Norm albuminuria ( $p$-value $=\mathbf{0 . 0 0 6}$ ).

\begin{tabular}{|c|c|c|c|}
\hline & $\begin{array}{c}\text { Healthy Control } \\
\mathbf{n = 4 0}\end{array}$ & $\begin{array}{c}\text { Norm- Albuminuria Subgroup } \\
\mathbf{n = 2 0}\end{array}$ & \multirow{2}{*}{$\boldsymbol{p}_{\text {-value }}$ * } \\
\cline { 1 - 3 } RBP & \multicolumn{3}{|c|}{0.056} \\
\hline Mean \pm SD & $6.35 \pm 0.5$ & $4.88 \pm 3.0$ & \\
\hline Minimum & 1.40 & 1.20 & \\
\hline Maximum & 8.60 & 11.50 & \\
\hline
\end{tabular}

Table (6) P-value $\leq 0.05$ is considered significant by One Way ANOVA

Table (7): urinary Concentration of Retinol Binding Protein (RBP) in the Healthy Control Subjects vs. Norm- Albuminuria Subgroup: It demonstrates that mean urinary concentration of Retinol Binding Protein (RBP) was non-significant in healthy control subjects as compared with patients with type II DM (Norm- Albuminuria Subgroup) with healthy control subjects.

\begin{tabular}{|c|c|c|c|c|c|}
\hline & $\begin{array}{c}\text { Norm albu- } \\
\text { minuria n= 20 }\end{array}$ & $\begin{array}{c}\text { Micro albu- } \\
\text { minuria n= 20 }\end{array}$ & $\begin{array}{c}\text { Macro albu- } \\
\text { minuria n= 20 }\end{array}$ & TOTAL & p-value* \\
\hline urinary Concentration of Retinol Binding Protein (RBP) & \multirow{2}{*}{ 0.001* } \\
\hline Mean \pm SD & $4.88 \pm 3.0$ & $7.03 \pm 2.4$ & $8.83 \pm 1.2$ & $6.91 \pm 0.4$ & \\
\hline Minimum & 1.20 & 2.00 & 5.40 & 1.20 & \\
\hline Maximum & 11.50 & 10.80 & 11.40 & 11.50 & \\
\hline
\end{tabular}


Table (8): urinary Concentration of Retinol Binding Protein (RBP) in the Healthy Control Subjects vs. Micro- Albuminuria Subgroup: It demonstrates that mean urinary concentration of Retinol Binding Protein (RBP) was higher in patients with type II DM (Micro- Albuminuria Subgroup) as compared with healthy control subjects but without a statistically significant difference $(\mathrm{P}=0.366)$.

\begin{tabular}{|c|c|c|c|}
\hline & $\begin{array}{c}\text { Healthy Control } \\
\mathbf{n = 4 0}\end{array}$ & $\begin{array}{c}\text { Micro- Albuminuria Subgroup } \\
\mathbf{n = 2 0}\end{array}$ & p-value* \\
\hline RBP & \multicolumn{3}{|c|}{} \\
\hline Mean \pm SD & $6.35 \pm 0.5$ & $7.03 \pm 2.4$ & \multirow{2}{*}{0.366} \\
\hline Minimum & 1.40 & 2.00 & \\
\hline Maximum & 8.60 & 10.80 & \\
\end{tabular}

Table (8): *p-value $\leq 0.05$ is considered significant by Independent Sample t-test.

Table (9): urinary Concentration of Retinol Binding Protein (RBP) in the Healthy Control Subjects vs. Macro- Albuminuria Subgroup: It demonstrates that mean urinary concentration of Retinol Binding Protein (RBP) were significantly higher in patients with type II DM (Macro- Albuminuria Subgroup) as compared with healthy control subjects $(\mathrm{P}=0.002)$.

Table (9): ${ }^{*} p$-value $\leq 0.05$ is considered significant by Independent Sample t-test.

\begin{tabular}{|c|c|c|c|}
\hline & $\begin{array}{c}\text { Healthy Control } \\
\mathbf{n}=\mathbf{4 0}\end{array}$ & $\begin{array}{c}\text { Macro- Albuminuria Subgroup } \\
\mathbf{n = 2 0}\end{array}$ & \multirow{2}{*}{$\boldsymbol{p}$-value } \\
\cline { 1 - 3 } RBP & \multicolumn{3}{|c|}{} \\
\hline Mean \pm SD & $6.35 \pm 0.5$ & $8.83 \pm 1.2$ & \multirow{2}{*}{$\mathbf{0 . 0 0 2 *}$} \\
\hline Minimum & 1.40 & 5.40 & \\
\hline Maximum & 8.60 & 11.40 & \\
\hline
\end{tabular}

\section{Discussion:}

Diabetic nephropathy (DN) is one of the major microvascular complications of diabetes and it is defined as a rise in the urinary albumin excretion (UAE) rate and abnormal renal function [7].Microalbuminuria is known to be the earliest clinical sign of diabetic nephropathy onset DN can affect negatively all cellular components in the both renal tubular interstitium and glomeruli [8].
Studies have also stated that micro albuminria may develop in non-diabetic patients with progressive chronic kidney disease so microalbuminuria is not specific for patients with DN alone Also, not all diabetic patients with microalbuminuria progress to end stage renal disease. Therefore, sensitive and specific biomarkers that can early predict susceptibility to diabetic nephropathy is needed [9]. 
Albuminuria is widely used to indicate early phases of diabetic nephropathy although it is limited by the fact that structural damage might precede albumin excretion. This necessitates identifying better biomarkers that diagnose or predict diabetic nephropathy [10]. Measurement of urinary biomarkers is more useful than measurement of serum biomarkers because Urine can be sampled simply and considered a non-invasive investigation [11].

The use of a panel with a combination of biomarkers instead of urinary albumin alone seems to be an interesting approach for early detection of DN, including markers of glomerular damage (e.g., albumin), tubular damage (e.g. RBP), inflammation (e.g. TNF- $\alpha$ ) and oxidative stress because these mechanisms contribute to the development and outcomes of this diseases [12].

Retinol Binding Protein (RBP) are a family of proteins with diverse functions. They are carrier proteins that bind retinol. Assessment of retinol-binding protein is used to determine visceral protein mass in health-related nutritional studies. Retinol and retinoic acid play crucial roles in the modulation of gene expression and overall development of an embryo [13]. We will discuss here the relation between urinary RBP level and different factors which affect patients with diabetic nephropathy.

Results in table (15) in our study demonstrates that mean urinary Concentration of Retinol Binding Protein (RBP) was higher in patients with type II DM as compared with healthy control subjects in patients and controls respectively and this results correlate with the following studies

There was a significant elevation of RBP levels in diabetic patients compared with healthy subjects. RBP showed significant positive correlations with triglyceride, systolic blood pressure, and urinary albumin excretion, and significant negative correlations with high-density lipoprotein cholesterol. And this is correlated within the study done by [14].

Increased urinary excretion of retinolbinding protein has been reported in patients with type 2 diabetes compared with healthy control subjects. Reduction in proximal tubule function results in increased excretion of these proteins in urine. Moreover, urinary levels of both retinol binding protein was elevated in some normoalbuminuric patients with diabetes.

In our study, Results in table (17) demonstrates that mean urinary Concentration of Retinol Binding Protein (RBP) was nonsignificant in healthy control subjects as compared with patients with type II DM (NormAlbuminuria Subgroup) with healthy control subjects.

Results in table (18) demonstrate that mean urinary Concentration of Retinol Binding Protein (RBP) was higher in patients with type II DM (Micro- Albuminuria Subgroup) as compared with healthy control subjects. 
Results in table (19) demonstrates that mean urinary Concentration of Retinol Binding Protein (RBP) were significantly higher in patients with type II DM (Macro- Albuminuria Subgroup) as compared with healthy control subjects The following studies agree with that elevation of urinary RBP correlate with degree of albuminuria.

In the study done by [15], the research was performed on 293 patients with T2DN who had been referred to the Department of Endocrinology of the Shanghai Traditional Chinese Medicine-Integrated Hospital (Shanghai, China) were enrolled. Subjects were divided into three groups according to their urine albumin/urine creatinine (UACR) ratio: normoalbuminuric group (UACR $300 \mathrm{mg} / \mathrm{g}, \mathrm{n}=93$ ). 50 healthy subjects were recruited as the control group.

Control group subjects were randomly selected Age- and gender matched non-diabetic controls were randomly selected from the Shanghai -Integrated Hospital for a comprehensive medical check-up, who had no prior history of diabetes, renal disease or cardiovascular diseases including hypertension and dyslipidemia were used for HbAlc analysis [15].

Urinary RBP levels were significantly correlated with UACR, BMI, Scr, BUN, TG, disease duration. Our results suggest that urinary levels of RBP may serve as novel biomarkers for the identification of type 2 diabetic nephropathy [15]. Another study done by [16].
In this study, we examined changes in urinary RBP level and its correlation with urinary albuminuria in T2DN patients. We found that the level of RBP in urine was significantly higher in the micro albuminuria and macro albuminuria patient groups compared with the normoalbuminuric and control groups. In addition, urine RBP levels were significantly and positively correlated with UACR, BMI, Scr, BUN, TG, disease duration

Results of this study correlates with ours in table 18 , Urinary RBP has been classically used as a marker of proximal tubular damage previous studies reported that the urinary excretion of RBP was enhanced in diabetic subjects compared with healthy controls, and found that RBP was associated with micro albuminuria more than healthy control, suggesting that RBP might act as a renal biomarker for predicting diabetic complications like albuminuria [16]. In this study, role of RBP more in macro albuminuric but less significant in normo and micro albuminuric patients.

Urinary RBP was also independently related to the risk for macroalbuminuric $\mathrm{DN}$ in diabetic patients, suggesting that RBP could be used as a marker for follow-up clinical monitoring of diabetics with DN; however, its role in normoalbuminuric and microalbuminuria in DN should be further explored [17]. BUT In contrast study was done in $\mathbf{2 0 1 6}$, by [18] showed that serum RBP concentration was positively associated with serum creatinine and eGFR with no correlation with uri- 
nary albumin / creatinine ratio AND THAT make RBP may be not significant biomarker in early detection of diabetic nephropathy.

The following study shows that level of urinary RBP in macroalbuminuric patient higher than microalbuminuria ones RBP has shown very good diagnostic value in patients with macroalbuminuria, but to a lesser degree in subjects known to have micro albuminuria in the current study. There is an increased urinary excretion of RBP with the progression of diabetic nephropathy as observed in our study, which was not affected by the metabolic status of the patients [10]. In our study, we showed that urinary RBP was significantly elevated in the microalbuminuria and macroalbuminuria groups compared with those in the normoalbuminuric and control groups.

\section{Recommendations:}

This study recommend the followings' RBP level can be used as a biomarker that participate in early diagnosis of diabetic nephropathy in patients with type 2 Diabetes mellitus. Large studies should be done to include larger number of patients and to verify the results of this study.

\section{References:}

1. American Diabetes Association. Diagnosis and classification of diabetes mellitus. Diabetes Care, 2019; 37(Suppl.1):S81-S90.

2. Akinsegun A, Akinola Olusola D, Sarah JO, Olajumoke O, Adewumi A, Olanrewaju A, Kingsley A. Mean platelet volume and platelet counts in type 2 diabetes: Mellitus on treatment and non-diabetic mellitus controls in lagos, nigeria. Pan Afr Med J. 2014; 18:42.

3. Korish AA, Abdel Gader AG, Arafah MM. Camel milk attenuates the biochemical and morphological features of diabetic nephropathy: Inhibition of smad1 and collagen type IV synthesis. Chem Biol Interac. 2015; 229:1008.

4. Thomas MC, Burns WC, Cooper ME. Tubular changes in early diabetic nephropathy. $A d v$ Chronic Kidney Dis. 2005; 12: 177-86.
5. Tramonti G, Kanwar YS. Review and discussion of tubular biomarkers in the diagnosis and management of diabetic nephropathy. Endocrine, 2013; 43: 494-503.

6. Takebayashi K, Suetsugu M, Wakabayashi S, Aso Y, Inukai T. Retinol binding protein-4 levels and clinical features of type 2 diabetes patients. J Clin Endocrinol Metab. 2007; 92: 2712-19.

7. Parving HH, Oxenboll B, Svendsen PA, Christiansen JS, Andersen AR. Early detection of patients at risk of developing diabetic nephropathy. A longitudinal study of urinary albumin excretion. Acta Endocrinal, (Copenh) 2005; 100: 550-55.

8. Fioretto P, Mauer M. Histopathology of diabetic nephropathy. Semin Nephrol. 2007; 27: 195-207. 
9. Garg, V. Novel urinary biomarkers in prediabetic nephropathy. Clin. Exp. Nephrol. 2015; 19: 895-900.

10. Al-Rubeaan K, Siddiqui K, Al-Ghonaim MA, AlNaqeb D. Assessment of the diagnostic value of different biomarkers in relation to various stages of diabetic nephropathy in type 2 diabetic patients. 2017.

11. Park SE, Kim WJ, Youn BS. High urinary ACE2 concentrations are associated with severity of glucose intolerance and microalbuminuria. Eur J Endocrinol. 2013; 168: 20310.

12. Graham TE, Ciaraldi TP, Oberbach A, Jansson PA, Smith U and Kahn BB. Retinolbinding protein 4 and insulin resistance in lean, obese, and diabetic subjects. $N$ Engl $J$ Med. 2006; 354: 2552-63.

13. Ciarimboli G, Lancaster CS, Schlatter E, Mathijssen V, Sprowl JA et al. Proximal tubular secretion of creatinine by organic cation transporter OCT2 in cancer patients, Clin. Cancer Res. 2012; 18 (4): 1101-8.
14. Salem MA, el-Habashy SA, Saei, Tawfik PH. Urinary excretion of n-acetyl-beta-Dglucosaminidase and retinol binding protein as alternative indicators of nephropathy in patients with type 1 diabetes mellitus. Pediatr Diabetes, 2003; 3: 37-41.

15. Wu J, Shao, Xie X, Zhu C. Urinary RBP and NGAL Levels are Associated with Nephropathy in Patients with Type 2 Diabetes. Cellular Physiology and Biochemistry, 2017; .42(2): 594-602.

16. Hong CY, Chia KS, Ling SL. Urinary protein excretion in type 2 diabetes with complications. J Diabetes Complications, 2000; 14:259-65.

17. Titan SM, Vieira JM Jr, Pereira AB. Urinary mcp-1 and rbp: Independent predictors of renal outcome in macroalbuminuric diabetic nephropathy. $J$ Diabetes Complications, 2012; 26: 546-53.

18. Kim Y, Park CW. New therapeutic agents in diabetic nephropathy. Korean J Intern Med. 2017; 32(1): 11-25. 